\title{
Interleukin-17A promotes the formation of inflammation in the lung tissues of rats with pulmonary fibrosis
}

\author{
WEI DING $^{1}$, XING-YI ZHANG ${ }^{1}$, MING PAN $^{1}$, BIN ZHAO $^{1}$, CHUANG CHEN $^{1}$, \\ ZHI-HAO NIU ${ }^{1}$, CHENG-LIANG HUANG ${ }^{2}$, YAN-YAN LI ${ }^{2}$, XIAN-MING FAN ${ }^{2}$, \\ YAN-MEI MA ${ }^{2}$, MING ZHANG ${ }^{2}$ and WEN-JUN ZHANG ${ }^{2}$ \\ ${ }^{1}$ Department of General Surgery, Second Hospital, Jilin University, Changchun, Jilin 130022; \\ ${ }^{2}$ Department of Respiratory Medicine, The Affiliated Hospital of Luzhou Medical College, \\ Luzhou, Sichuan 646000, P.R. China
}

Received August 29, 2014; Accepted May 1, 2015

DOI: $10.3892 /$ etm.2015.2564

\begin{abstract}
The aim of the present study was to investigate the effects of interleukin (IL)-17A in a rat model of pulmonary fibrosis. In total, 20 female Wistar rats were randomly divided into a normal saline (NS group) and a bleomycin group (BLM group). The BLM group rats were intratracheally instilled with BLM, while the NS group rats were intratracheally instilled with saline. In each group, half the rats were sacrificed at day 7 and day 28 , respectively, following intratracheal instillation. Subsequently, hematoxylin and eosin and Masson's trichrome staining were performed to observe the pathological changes in the lung tissue, while the expression of IL-17A in the lung tissue was detected by immunohistochemistry. In addition, the bronchoalveolar lavage fluid (BALF) was collected and divided into two sections. One section was used for cell counting and classification, and an ELISA was performed to detect the concentration of IL-17A in the BALF. The additional section was used to separate, purify and cultivate alveolar macrophages (AMs). The concentration of IL-17A in the cultivating supernatant was detected by ELISA, and the mRNA expression levels of IL-17A in the AMs were detected using reverse transcription-polymerase chain reaction (RT-PCR). The results revealed that a considerable number of inflammatory cells had infiltrated into the alveolar cavity in the BLM group at day 7, and less alveolitis and more serious fibrosis were observed at day 28 , as compared with the NS group. Furthermore, when compared with the NS group, the protein expression levels of IL-17A in the lung tissue were markedly higher in the BLM group at days 7 and 28 (higher
\end{abstract}

Correspondence to: Dr Xian-Ming Fan, Department of Respiratory Medicine, The Affiliated Hospital of Luzhou Medical College, 25 Taiping Street, Luzhou, Sichuan 646000, P.R. China E-mail: fanxianming_fxm@163.com

Key words: interleukin-17A, pulmonary fibrosis, pulmonary inflammation at day $7 ; \mathrm{P}<0.05)$. In addition, the total number of BALF cells in the BLM group was clearly higher at day 7 when compared with the NS group $(\mathrm{P}<0.05)$, although a normal level was re-established by day 28 . The level of IL-17A in the BALF increased significantly at days 7 and 28 in the BLM group; however, when compared with the level at day 7, the concentration had decreased at day 28 . When compared with the NS group, the protein expression levels of IL-17A in the BLM group were notably higher after 12, 24 and $48 \mathrm{~h}$. In addition, the results of the RT-PCR assay revealed that the mRNA expression levels of IL-17A increased significantly at days 7 and 28 in the BLM group when compared with the NS group $(\mathrm{P}<0.05)$. Therefore, IL-17A was demonstrated to promote the development of pulmonary inflammation, which may be involved in the development of pulmonary fibrosis.

\section{Introduction}

Idiopathic pulmonary fibrosis (IPF) is an interstitial lung disease that is characterized by the pathological conditions of common interstitial pneumonia (1). The etiology of IPF remains unknown, although the disease primarily occurs in adults, with pathological changes limited to the lungs and a progressive development (2). Due to the unknown pathogenesis and the challenges associated with diagnosis, there is a lack of an effective treatment and the prognosis is poor; the average survival time is only $2.8-4.2$ years following a diagnosis of IPF (1). Therefore, investigations into the etiology and pathogenesis of IPF are necessary in order to identify an effective treatment.

Previous studies have demonstrated that interleukin (IL)-17A is a proinflammatory cytokine that is involved in chronic inflammation and autoimmune diseases (3). In the study by Mi et al (3), components of the IL-17A signaling pathway were hypothesized to become new potential molecular therapy targets in the treatment of pulmonary fibrosis.

The aim of the present study was to investigate the role of IL-17A in the pathogenesis of pulmonary fibrosis, and lay a solid foundation for the further exploration of new molecularly-targeted therapeutic agents in the treatment of IPF. Bleomycin (BLM) is a glycopeptide antitumor antibiotic and 
antiviral drug produced by bacterium, which was initially produced in 1966 (4). As an anticancer agent, BLM is used to treat Hodgkin's lymphoma, squamous cell carcinomas and testicular cancer. The most serious complication of BLM is pulmonary fibrosis and impaired lung function (5); therefore, BLM was used in the present study to induce pulmonary fibrosis and impair lung function.

\section{Materials and methods}

Materials. The present study was approved by the ethics committee of the Affiliated Hospital of Luzhou Medical College (Luzhou, China). A total of 20 female Wistar rats (weight, 180-200 g) were purchased from Chongqing Teng Xin Bill Experimental Animal Sales Co. Ltd. (Chongqing, China) for use in the study. The reagents used in the experiment were purchased from the following companies. Pentobarbital sodium was obtained from Jiangsu Hengrui Medicine Co. Ltd. (Lianyungang, China), while bleomycin A5 was purchased from Harbin Pharmaceutical Co. Ltd, (Shanghai, China). A rabbit anti-IL-17 immunohistochemistry kit was purchased from Beijing Boosen Biological Technology Co. Ltd. (Beijing, China), and the IL-17A ELISA kit was obtained from Bio-Rad Laboratories, Inc. (Hercules, CA, USA). A total RNA extraction kit was obtained from Tiangen Biotech Co. Ltd. (Beijing, China), while improved RPMI-1640 culture medium, 1X Dulbecco's modified Eagle's medium (DMEM) in high glucose medium and fetal bovine serum were all purchased from HyClone (GE Healthcare, Logan, UT, USA). Primers for polymerase chain reaction (PCR) were purchased from Shanghai Sangon Biological Engineering Co. Ltd. (Shanghai, China), and the RNA reverse transcription (RT) and PCR kits were purchased from Chengdu FOREGENE Biotechnology Co. Ltd. (Chengdu, China).

Establishment of an animal model of pulmonary fibrosis. A total of 20 female Wistar rats were randomly divided into a control group (normal saline, NS) and a model group (BLM). Model establishment was conducted according to previously described methods (6). The rats in the BLM group were anesthetized by an intraperitoneal injection of pentobarbital sodium ( $40 \mathrm{mg} / \mathrm{kg}$ body weight) and the trachea was exposed according to a blunt separation method during aseptic surgery. The trachea was filled with $0.3 \mathrm{ml} \mathrm{NS}$ and BLM A5 $(5 \mathrm{mg} / \mathrm{kg})$, after which the rats were quickly erected and spun to distribute the liquid in the lung evenly. With regard to the NS group, the same methods were applied, but with an injection of the same volume of NS in the rat tracheas.

Specimens and pathological analysis of the lung tissue. Experimental animals from the two groups were sacrificed with $10 \%$ chloral hydrate $(3 \mathrm{ml} / \mathrm{kg})$ and right ventricular blood sampling was performed following intratracheal instillation of NS or BLM at week one (day 7, n=10) and week four (day 28, $\mathrm{n}=10$ ). Collection of the lung tissue and bronchoalveolar lavage fluid (BALF) was conducted according to previously described methods (7). A total of $40 \mathrm{~g} / 1$ paraformaldehyde was injected into the left pulmonary tissue for fixation. Following paraffin embedding, three sections collected from different parts of the lung tissue were sliced to a thickness of $5 \mu \mathrm{m}$. Hematoxylin and eosin and Masson's trichrome staining were used to evaluate the pathological changes (alveolitis and pulmonary fibrosis) in the pulmonary tissue, with the specific criterion predominantly formed according to previous studies $(8,9)$. Briefly, pathological changes were graded according to the Edmondson-Steiner grading method. Grade I, highly differentiated cancer cells, mucleocytoplasmic ratio is close to normal; grade II, moderately differentiated cancer cells, mucleocytoplasmic ratio increases with deeper nuclear staining; grade III, highly differentiated cancer cells, mucleocytoplasmic ratio is increases with marked heterogenous nuclear division; and grade IV, highest differentiation of cancer cells, reduced cytoplasm, densely stained chromatin, irregular cell shape and loose arrangement.

Immunohistochemical staining for IL-17 in the lung tissue. Lung tissue slices were subjected to dewaxing, hydration, antigen repair and serum blocking. The primary antibody used was a rabbit anti-IL-17 polyclonal antibody (dilution, 1:100; cat. no. sc-7927; Santa Cruz Biotechnology, Inc., Dallas, TX, USA), and the secondary antibody used was a goat anti-rabbit antibody (dilution 1:100; cat. no. sc-45101; Santa Cruz Biotechnology, Inc.) with the Dako REAL ${ }^{\mathrm{TM}}$ Envision $^{\mathrm{TM}}$ kit (Dako, Glostrup, Denmark). The marker used was horseradish peroxidase, while 3,3'-diaminobenzidine solution (Beijing Solarbio Science \& Technology Co., Ltd., Beijing, China) was used for visualization. Other steps included hematoxylin counterstaining, dehydration using an ascending concentration of ethanol followed by treatment with xylene and mounting. The control group was treated with phosphate-buffered saline instead of the primary antibody. The image results of the immunohistochemical staining were acquired with a Leica system (Leica DMi8; Leica Microsystems, Inc., Buffalo Grove, IL, USA) and analysis was performed using Image-Pro Plus software (version 6.0; Media Cybernetics, Inc., Rockville, MD, USA). The average absorbance of the positive staining was calculated through randomly selected, stained lung tissue areas of five high power fields at two time points using ImageJ $1.48 \mathrm{u}$ software (National Institutes of Health, Bethesda, MD, USA).

Counting and classification of BALF cells. According to previously described methods (10), BALF cells were counted and classified. A total of $10 \mu$ BALF cell suspension liquid was inserted into a cell counting plate (Costar, Corning Life Sciences, Tewkesbury, MA, USA), and the number of cells was counted in the four large squares at the four corners at a low magnification (IX83; Olympus Corporation, Tokyo, Japan). A sedimentation smear was taken and Wright's stain (Sigma-Aldrich, St. Louis, MO, USA) cell sorting was used to select 100 white blood cells to count according to their morphological characteristics. The percentage of the various white blood cell types was calculated. In addition, the absolute value of the various white blood cell types in the BALF were determined by counting the total cell number. The formula was as follows: Cell number $/ \mathrm{ml}=\mathrm{N} / 4 \times 10 \times \mathrm{C} \times 10^{6}$, where $\mathrm{N}$ was the total number of white blood cells in four large squares and $\mathrm{C}$ was the dilution ratio. 
Table I. Comparison of pulmonary alveolitis and fibrosis in the rats from the two groups $(\mathrm{n}=5)$.

\begin{tabular}{|c|c|c|c|c|}
\hline \multirow[b]{2}{*}{ Group } & \multicolumn{2}{|c|}{ Alveolitis score } & \multicolumn{2}{|c|}{ Pulmonary fibrosis score } \\
\hline & Day 7 & Day 28 & Day 7 & Day 28 \\
\hline NS & $1.00 \pm 0.00$ & $1.00 \pm 0.00$ & $1.00 \pm 0.00$ & $1.00 \pm 0.00$ \\
\hline BLM & $3.60 \pm 0.55^{\mathrm{a}}$ & $1.40 \pm 0.55^{\mathrm{a}}$ & $1.60 \pm 0.55^{\mathrm{a}}$ & $3.80 \pm 0.45^{\mathrm{a}}$ \\
\hline
\end{tabular}

Pathological changes were graded according to the Edmondson-Steiner method. Data are presented as the mean \pm standard deviation. ${ }^{a} \mathrm{P}<0.05$, vs. NS group. NS, normal saline; BLM, bleomycin.

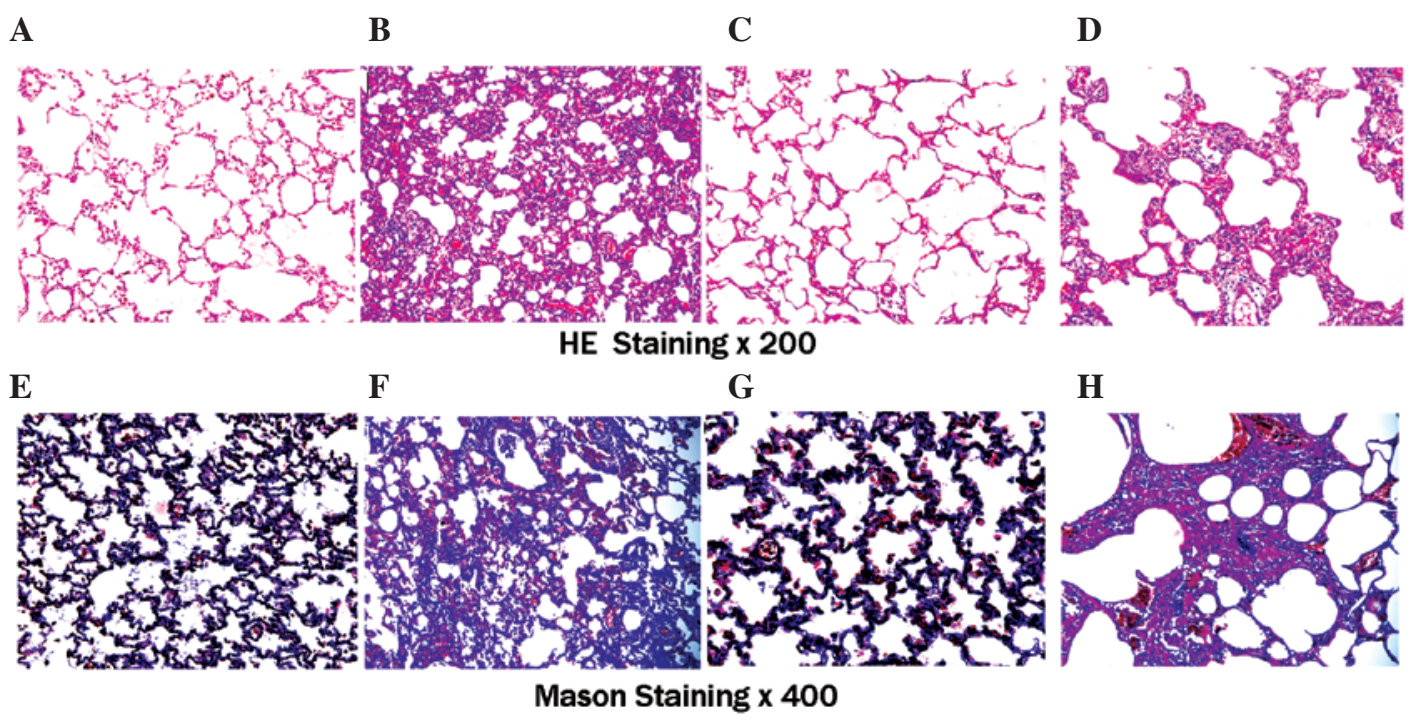

Figure 1. Alveolitis and pulmonary fibrosis of the lung tissues in the two groups of rats at days 7 and 28, as observed by HE and Masson's trichrome staining. (A and E) NS group (day 7); (B and F) BLM group (day 7); (C and G) NS group (day 28); (D and H) BLM group (day 28). HE, hematoxylin and eosin; NS, normal saline; BLM, bleomycin.

Using ELISA to detect the levels of IL-17A in the BALF. Levels of IL-17A in the BALF were detected using an ELISA kit, according to the manufacturer's instructions.

Separation, purification and cultivation of alveolar macrophages $(A M s)$. BALF was collected using a right pulmonary bronchoalveolar lavage, and the cell suspension was mixed with RPMI-1640 medium containing $100 \mathrm{ml} / \mathrm{l}$ calf serum, which was followed by incubation and purification for $3 \mathrm{~h}$ at $37^{\circ} \mathrm{C}$ in a $50 \mathrm{ml} / 1 \mathrm{CO}_{2}$ cell culture box (Thermo Scientific 3913 incubator; Thermo Fisher Scientific, Inc., Waltham, MA, USA). Subsequently, the culture fluid was discarded and the purified and adherent AMs were cultured in DMEM. Two groups of AMs (day 7 and day 28) were cultivated at a density of $5 \times 10^{5}$ cells/well in six-well plates. Following culture for 12,24 and $48 \mathrm{~h}$, the cells and the culture supernatant were collected. The supernatant was used for the detection of the IL-17A concentration, while the cells were used for the detection of IL-17A mRNA expression.

Detecting the expression of IL-17A mRNA in AMs using $R T-P C R$. Using the sequence of rat IL-17A mRNA, as listed in the PubMed database (US National Library of Medicine, National Institutes of Health), IL-17A primers were
Table II. Cell types in the bronchoalveolar lavage fluid at different time points.

\begin{tabular}{llrr}
\hline Group & Cell type & Day $7(\%)$ & Day 28 (\%) \\
\hline \multirow{2}{*}{ NS } & Macrophage & $90.20 \pm 1.64$ & $90.40 \pm 1.14$ \\
& Neutrophil & $3.00 \pm 0.71$ & $3.20 \pm 0.84$ \\
& Lymphocyte & $6.80 \pm 1.10$ & $6.40 \pm 0.54$ \\
\multirow{2}{*}{ BLM } & Macrophage & $71.40 \pm 2.70^{\mathrm{a}}$ & $89.40 \pm 1.14$ \\
& Neutrophil & $17.60 \pm 3.05^{\mathrm{a}}$ & $3.00 \pm 0.71$ \\
& Lymphocyte & $11.00 \pm 0.71^{\mathrm{a}}$ & $7.20 \pm 0.84$
\end{tabular}

Data are presented as the mean \pm standard deviation. ${ }^{a} \mathrm{P}<0.05$, vs. NS group. NS, normal saline; BLM, bleomycin.

designed and synthesized by Shanghai Sangon Biological Engineering Co. Ltd. Glyceraldehyde 3-phosphate dehydrogenase (GAPDH) was used as the internal reference. The primer sequences were as follows: IL-17A (188 bp) upstream primer, 5'-CTACCTCAACCGTTCCACT-3' and downstream primer, 5'-TTCTCAGGCTCCCTCTTC-3'; GAPDH (450 bp) upstream primer, 5'-ACCACAGTCCATGCCATCAC-3' and 
Table III. Changes in the supernatant concentration $(\mathrm{pg} / \mathrm{ml})$ of IL-17A at different culturing stages of the alveolar macrophages at day 7 and day 28 .

\begin{tabular}{|c|c|c|c|c|c|c|}
\hline \multirow[b]{2}{*}{ Group } & \multicolumn{3}{|c|}{ Day 7} & \multicolumn{3}{|c|}{ Day 28} \\
\hline & $12 \mathrm{~h}$ & $24 \mathrm{~h}$ & $48 \mathrm{~h}$ & $12 \mathrm{~h}$ & $24 \mathrm{~h}$ & $48 \mathrm{~h}$ \\
\hline NS & $0.34 \pm 0.05$ & $0.67 \pm 0.05$ & $0.96 \pm 0.04$ & $0.35 \pm 0.06$ & $0.66 \pm 0.06$ & $0.95 \pm 0.05$ \\
\hline BLM & $0.94 \pm 0.05^{\mathrm{a}}$ & $1.67 \pm 0.09^{\mathrm{a}}$ & $2.13 \pm 0.08^{a}$ & $0.85 \pm 0.08^{\mathrm{a}}$ & $1.42 \pm 0.05^{\mathrm{a}}$ & $1.92 \pm 0.06^{\mathrm{a}}$ \\
\hline
\end{tabular}

Data are presented as mean \pm standard deviation. ${ }^{\text {a }}<0.05$, vs NS group. NS, normal saline; BLM, bleomycin; IL, interleukin.

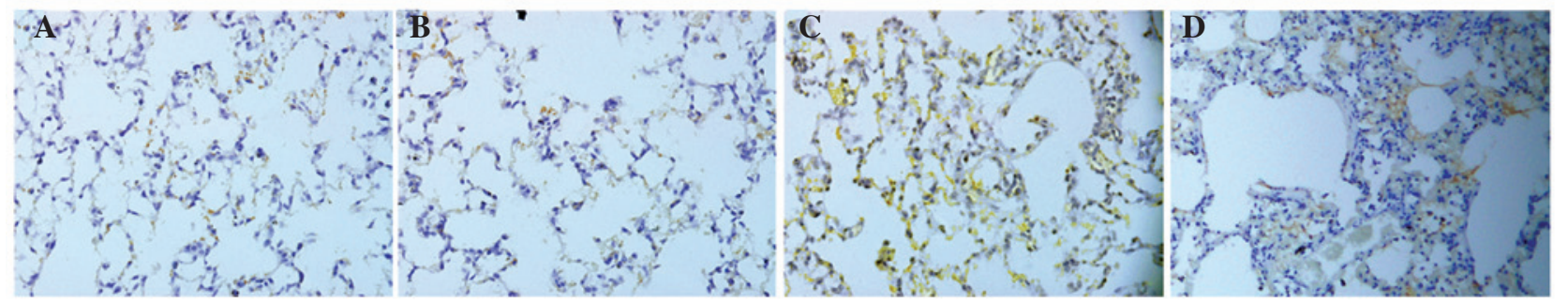

Figure 2. Expression of interleukin-17A in the lung tissues of rats, as observed by immunohistochemical staining (magnification, $\mathrm{x} 400$ ). (A) NS group (day 7); (B) NS group (day 28); (C) BLM group (day 7); (D) BLM group (day 28). NS, normal saline; BLM, bleomycin.

downstream primer, 5'-TCCACCACCCTGTTGCTGTA-3'. A TRIzol ${ }^{\circledR}$ kit was used to extract the total RNA from the AMs. The synthesis of cDNA by RT and the RT-PCR assay were carried out in strict accordance with the manufacturer's instructions. The PCR cycling conditions were as follows: Denaturation at $90^{\circ} \mathrm{C}$ for $5 \mathrm{~min}$, amplification and quantification at $90^{\circ} \mathrm{C}$ for $30 \mathrm{sec}, 60^{\circ} \mathrm{C}$ for $30 \mathrm{sec}$ and $72^{\circ} \mathrm{C}$ for $30 \mathrm{sec}$ for 30 cycles, followed by a final extension step at $72^{\circ} \mathrm{C}$ for $7 \mathrm{~min}$. The odds ratios for the samples, where GAPDH was used as the reference gene, were used to determine the expression quantity of IL-17A mRNA.

Statistical analysis. Data are presented as the mean \pm standard deviation, and were analyzed using SPSS software (version 13.0; SPSS, Inc., Chicago, IL, USA). The statistical significance of differences was assessed using one-way analysis of variance and Dixon's Q test, where $\mathrm{P}<0.05$ was considered to indicate a statistically significant difference.

\section{Results}

Pathological changes in the lung tissues from the two groups of rats. Inflammatory cell infiltration was observed in the alveolar cavity and pulmonary interstitium of the experimental group rats at day 7 , and alveolar septal thickening and a small amount of collagen fiber organization was observed in the lung interstitium. At day 28, the alveolar exudate had decreased and the alveolar structure was destroyed. Furthermore, the interstitial gap had widened significantly and hyperplasia of the extracellular matrix was evident. Fibroblast proliferation was also observed in the pulmonary interstitium, and the accumulation of collagen fibers had formed extensive fibrosis. When compared with the NS group, the alveolitis was evident in the BLM group at day 7. By day 28 , the alveolitis was relieved; however, the degree of pulmonary fibrosis remained high (Fig. 1, Table I).

Immunohistochemical detection of the protein expression of $I L-17 A$ in the lung tissue. Weak expression of IL-17A was observed in the lung tissues from the NS rats; the expression levels were $23.67 \pm 3.19$ and $24.26 \pm 3.35$ at days 7 and 28 , respectively. However, the expression of IL-17A in the BLM group was significantly increased at days $7(103.48 \pm 9.49)$ and $28(87.42 \pm 7.64)$. When compared with the NS group at day 7 , the difference was statistically significant $(P<0.05)$, although expression levels decreased at day 28 compared with day 7 (Fig. 2).

Analysis of the BALF cell number and type. At day 7, the total number of BALF cells in the NS group was $9.45 \pm 0.76$, while the number of BALF cells in the BLM group was $35.28 \pm 2.76$. When compared with the NS group, the total number of BALF cells increased significantly in the BLM group and the difference was statistically significant $(\mathrm{P}<0.05)$. At day 28 , the total number of BALF cells in the NS group was $9.52 \pm 0.67$, while the number in the BLM group was 9.71 \pm 0.80 ; thus, no statistically significant difference was observed $(\mathrm{P}>0.05)$. When compared with the NS group, the AM ratio of BALF at day 7 was smaller in the BLM group. In addition, the percentages of neutrophils and lymphocytes were significantly increased, with the differences statistically significant $(\mathrm{P}<0.05)$. When compared with the NS group, the classification percentage of BALF cells in the BLM group at day 28 was not significantly different $(\mathrm{P}>0.05$; Table II), which demonstrated that the cell types had returned to normal.

Detection of IL-17A in the BALF. IL-17A levels in the BALF of the NS group were $57.45 \pm 6.68 \mathrm{pg} / \mathrm{ml}$ at day 7 and 
A

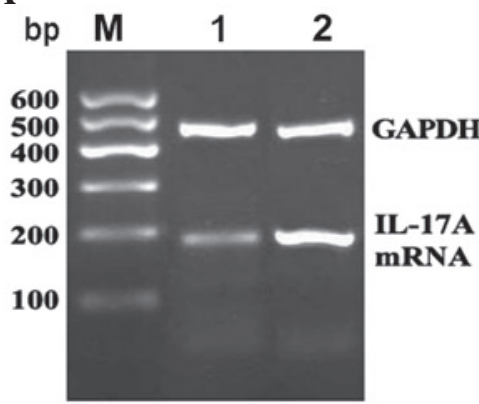

$12(h)$
B

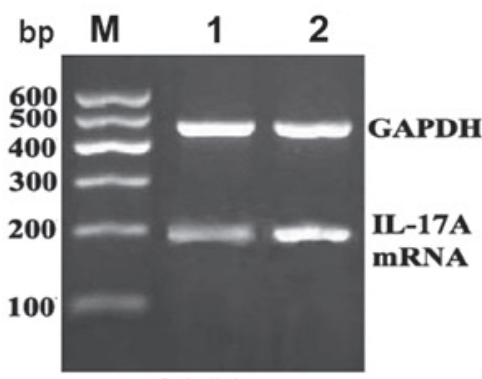

$24(h)$
C

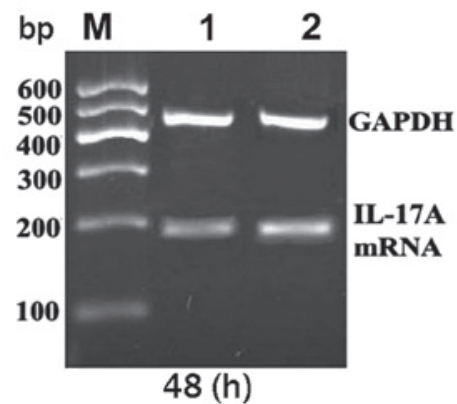

Figure 3. Expression of IL-17A mRNA in the alveolar macrophages at (A) $12 \mathrm{~h}$, (B) $24 \mathrm{~h}$ and (C) $48 \mathrm{~h}$ at day 7. Lane M, DNA marker; lane 1, normal saline group; lane 2, bleomycin group. IL, interleukin; GAPDH, glyceraldehyde 3-phosphate dehydrogenase.

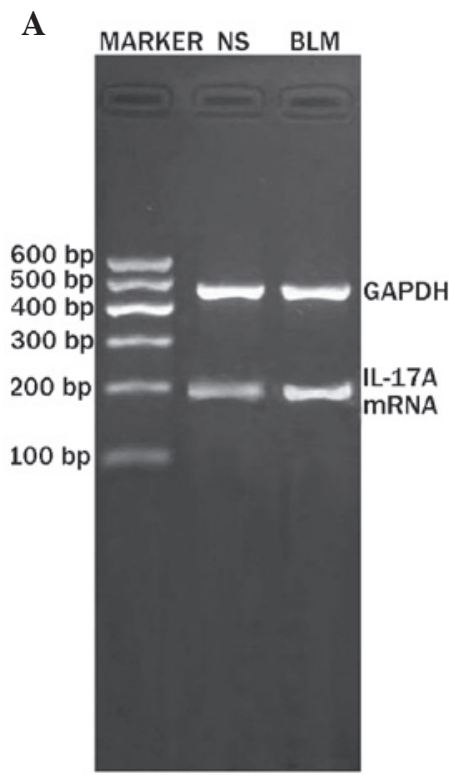

$12(h)$

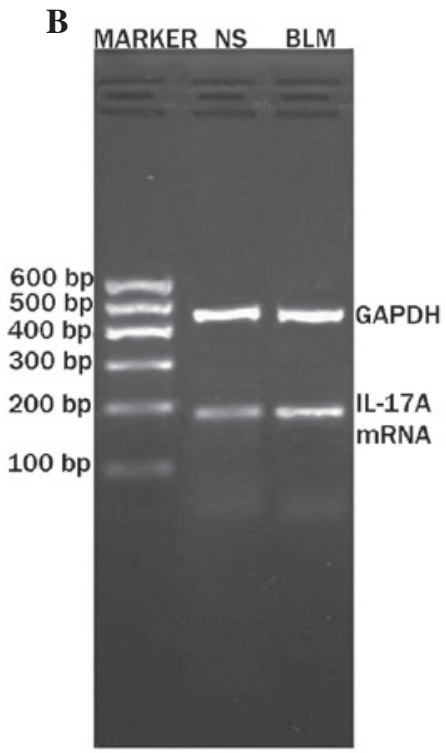

$24(h)$

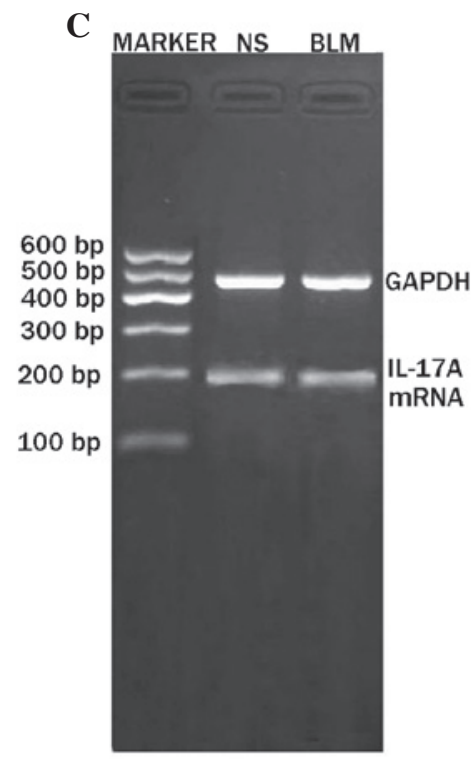

$48(h)$

Figure 4. Expression of IL-17A mRNA in the alveolar macrophages at (A) $12 \mathrm{~h}$, (B) $24 \mathrm{~h}$ and (C) $48 \mathrm{~h}$ at day 28. NS, normal saline; BLM, bleomycin; IL, interleukin; GAPDH, glyceraldehyde 3-phosphate dehydrogenase.

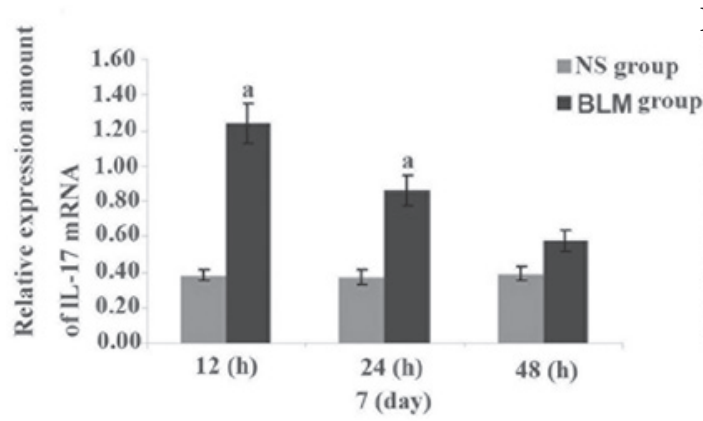

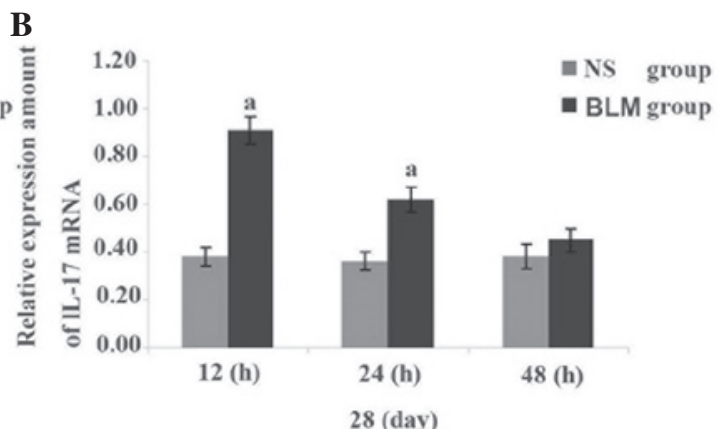

Figure 5. Relative expression of IL-17A mRNA in the alveolar macrophages at the different time points in the (A) day 7 and (B) day 28 groups. ${ }^{a} \mathrm{P}<0.05$, vs. NS group. NS, normal saline; BLM, bleomycin; IL, interleukin.

$55.49 \pm 6.06 \mathrm{pg} / \mathrm{ml}$ at day 28 , while the levels of IL-17A in the BLM group were $278.37 \pm 13.99$ and $213.26 \pm 11.62 \mathrm{pg} / \mathrm{ml}$ at days 7 and 28 , respectively. When compared with the NS group, the IL-17A levels were significantly increased in the BLM group and the difference was statistically significant $(\mathrm{P}<0.01)$. The level of IL-17A at day 28 was marginally lower compared with those on day 7; however, the difference was not statistically significant.

Changes in the concentration of IL-17A in the supernatant at different culture stages of the AMs. Compared with the NS group, the IL-17A concentration in the supernatant of the 
BLM group at days 7 and 28 increased significantly prior to AM culturing at 12, 24 and $48 \mathrm{~h}$. The differences between the two groups were statistically significant $(\mathrm{P}<0.05$, Table III).

Expression of IL-17A mRNA in the AMs. Expression levels of IL-17A mRNA at days 7 and 28 were higher in the BLM group when compared with the NS group, and the differences were statistically significant $(\mathrm{P}<0.05)$. The difference in expression was particularly notable in the first $12 \mathrm{~h}$, decreasing after 24 and $48 \mathrm{~h}$ (Figs. 3, 4 and 5).

\section{Discussion}

The pathogenesis of IPF is generally considered to result from the abnormal proliferation of epithelial cells and re-epithelialization repair, which leads to pulmonary fibrosis following alveolar epithelial cell damage due to inflammation (1). Previous studies have demonstrated that the overexpression of IL-17A, an important proinflammatory cytokine, may lead to chronic inflammation and autoimmune diseases $(11,12)$, while antibodies targeting anti-IL-17A and the anti-IL-17A receptor have demonstrated a particular effect for the treatment of immune diseases, such as ankylosing spondylitis and psoriasis, by inhibiting IL-17A or IL-17A receptors (13-15). Therefore, anti-IL-17A antibodies may have potential for the treatment of IPF.

In the present study, the expression of IL-17A in the lung tissue of rats with pulmonary fibrosis was analyzed under pulmonary inflammatory conditions. The results revealed that the expression of IL-17A in the lung tissue and the secretion of IL-17A in the AMs were increased during the occurrence and development of pulmonary fibrosis. IL-17A expression was more evident during the alveolar inflammation stage, indicating that IL-17A may contribute to the formation of alveolitis and subsequently result in pulmonary fibrosis. The results provide a theoretical basis for the targeted therapy of IPF in future research.

IL-17A is an important proinflammatory cytokine that belongs to the IL-17 family. The present view considers IL-17A to play an important role in the process of resistance to the invasion of certain pathogens, in addition to the induction and maintenance of chronic inflammation (3). Wilson et al (16) demonstrated that BLM-induced pulmonary fibrosis was mediated by IL-17A, while IL-17A-induced pulmonary fibrosis was dependent on transforming growth factor- $\beta$. Large-dose injections of IL-17A in the airway have been shown to induce pulmonary fibrosis, indicating that IL-17A and other cytokines may exert a synergistic effect on the occurrence and development of pulmonary fibrosis. Gasse et al (17) also found that the expression of IL-17A was increased during the early stages of BLM-induced lung injury, and confirmed that IL-17A and the IL-17A signaling transduction pathway were involved in the early alveolar inflammation induced by BLM in gene-deficient mice and neutralizing antibody-treated mice. Neutralizing the activity of IL-17A can improve the lung function of mice with pulmonary fibrosis (18). The results of the present study revealed that the total number of BALF cells in the BLM group increased significantly at day 7 when compared with the NS group. In addition, the ratio of neutrophils and lymphocytes increased significantly in the BLM group, while the ratio of AMs decreased significantly. In the BLM group, the expression levels of IL-17A in the BALF and the lung tissue were increased significantly at days 7 and 28 . These results demonstrated that IL-17A, as an inflammatory cell factor, may have a stronger chemotactic aggregation role in neutrophil cells and other inflammatory cell types, which may also play a very important role in the process of alveolitis and pulmonary fibrosis. These observations were consistent with the results of Mi et al (3), Wilson et al (16) and Gasse et al (17).

Abnormal AM activation can result in the abnormal expression of cytokines, which has an important role in the regulation of lung inflammation, and may affect the development of pulmonary fibrosis through a variety of mechanisms (19). In the present study, the application of ELISA was used to detect the concentration of IL-17A in the supernatant of the AMs from different culture periods. The results revealed that the expression levels of IL-17A in the culture supernatant of the AMs were increased significantly at days 7 and 28 in the BLM group, as compared with the NS group. The difference in expression was particularly notable in the first $12 \mathrm{~h}$, and decreased after 24 and $48 \mathrm{~h}$, which confirmed that AMs are able to secrete IL-17A, which may be involved in the formation of pulmonary fibrosis. When compared with the BLM group at day 7, the expression of IL-17A in the culture supernatant of the AMs was higher compared with the levels observed at day 28 , which also demonstrated that IL-17A may play an important role in the formation and development of pulmonary fibrosis. In addition, the role of IL-17A may be more significant in the alveolar inflammation stage, as compared with the pulmonary fibrosis stage. Using RT-PCR to detect the mRNA expression levels of IL-17A in the AMs, the results revealed that the mRNA expression levels of IL-17A in the AMs at different culture periods were significantly increased in the BLM group at days 7 and 28, particularly in the first $12 \mathrm{~h}$, when compared with the NS group. The expression of IL-17A was shown to gradually weaken after 24 and $48 \mathrm{~h}$, indicating that the expression of IL-17A mRNA gradually decreased due to the culture of AMs in vitro without the participation of an inducer. This further confirmed that the secretion of IL-17A was induced by AMs, and a substantial secretion was observed after stimulation, indicating that IL-17A is involved in the formation of pulmonary fibrosis. Furthermore, the results of the current study revealed that the mRNA expression of IL-17A in the AM medium of the BLM group at day 7 was higher compared with the levels at day 28 , which further confirmed that IL-17A may play an important role in the pathological process and development of pulmonary fibrosis, particularly in the alveolitis stage. Therefore, neutralization of IL-17A may be a promising therapeutic measure for the treatment of IPF, and future studies should focus on this research direction.

In conclusion, the present study indicated that IL-17A was able to promote the development of pulmonary inflammation in lung tissue, thus suggesting it may have an important role in the development of pulmonary fibrosis. Neutralization of IL-17A may be used to treat IPF; however, further research is required. 


\section{Acknowledgements}

The study was supported by a grant from the Science and Technology Bureau of Luzhou City (no. 12102).

\section{References}

1. Tanaka K, Ishihara T, Azuma A, Kudoh S, Ebina M, Nukiwa T, Sugiyama Y, Tasaka Y, Namba T, Ishihara T, Sato K, Mizushima Y and Mizushima T: Therapeutic effect of lecithinized superoxide dismutase on bleomycin-induced pulmonary fibrosis. Am J Physiol Lung Cell Mol Hysiol 298: L348-L360, 2010.

2. Raghu G, Collard HR, Egan JJ, Martinez FJ, Behr J, et al; ATS/ERS/JRS/ALAT Committee on Idiopathic Pulmonary Fibrosis: An official ATS/ERS/JRS/ALAT statement: Idiopathic pulmonary fibrosis: Evidence-based guidelines for diagnosis and management. Am J Respir Crit Care Med 183: 788-824, 2011.

3. Mi S, Li Z, Yang HZ, Liu H, Wang JP, Ma YG, Wang XX, Liu HZ, Sun W and Hu ZW: Blocking IL-17A promotes the resolution of pulmonary inflammation and fibrosis via TGF-beta 1-dependent and -independent mechanisms. J Immunol 187: 3003-3014, 2011.

4. Umezawa H, Maeda K, Takeuchi T and Okami Y: New antibiotics, bleomycin A and B. J Antibiot (Tokyo) 19: 200-209, 1966.

5. Hoshino T, Okamoto M, Sakazaki Y, Kato S, Young HA and Aizawa $\mathrm{H}$ : Role of proinflammatory cytokines IL-18 and IL-1beta in bleomycin-induced lung injury in humans and mice. Am J Respir Cell Mol Biol 41 661-670, 2009.

6. Huang CL, Wang WJ, Zhu HL, Fan XM, Chen JP, Zhan XQ and $\mathrm{Li} Y \mathrm{Y}$ : Effect of andrographolide on expression of hydroxyproline and PDGF in lung tissue of bleomycin-induced rat pulmonary fibrosis. Shizhen Guo Yi Guo Yao 23: 904-907, 2012 (In Chinese).

7. Huang C, Li Y, Fan X, Wang W and Zhan X: Effects of combination of Salvia and Ligustrazine on TNF- $\alpha$ and TGF- $\beta 1$ in serum and BALF of rats with pulmonary fibrosis. Xi Bao Yu Fen Zi Mian Yi Xue Za Zhi 29: 673-676, 2013 (In Chinese).

8. Tabata C, Kubo H, Tabata R, Wada M, Sakuma K, Ichikawa M, Fujita S, Mio T and Mishima M: All-trans retinoic acid modulates radiation-induced proliferation of lung fibroblasts via IL-6/IL-6R system. Am J Physiol Lung Cell Mol Physiol 290: L597-L606, 2006.
9. Lee KY, Ito K, Hayashi R, Jazrawi EP, Barnes PJ and Adcock M NF-kappa B and activator protein 1 response elements and the role of histone modifications in IL-1 beta-induced TGF-beta 1 gene transcription. J Immunol 176: 603-615, 2006.

10. Liu JP, Di NL, Fan XM, Li SC and Zhang SP: The expressions of STAT1 and PDGF in lung tissue of rats with pulmonary fibrosis induced by bleomycin. Shan Dong Yi Yao 31: 16-18, 2008 (In Chinese).

11. Halwani R, Al-Muhsen S and Hamid Q: T helper 17 cells in airway diseases: From laboratory bench to bedside. Chest 143: 494-501, 2013

12. Truchetet ME, Mossalayi MD and Boniface K: IL-17 in the rheumatologist's line of sight. Biomed Res Int 2013: 295132, 2013.

13. Baeten D, Baraliakos X, Braun J, Sieper J, Emery P, et al: Anti-interleukin-17A monoclonal antibody secukinumab in treatment of ankylosing spondylitis: A randomised, double-blind, placebo-controlled trial. Lancet 382: 1705-1713, 2013.

14. Leonardi C, Matheson R, Zachariae C, Cameron G, Li L, Edson-Heredia E, Braun D and Banerjee S: Anti-interleukin-17 monoclonal antibody ixekizumab in chronic plaque psoriasis N Engl J Med 366: 1190-1199, 2012.

15. Papp KA, Leonardi C, Menter A, Ortonne JP, Krueger JG, Kricorian G, Aras G, Li J, Russell CB, Thompson EH and Baumgartner S: Brodalumab, an anti-interleukin-17-receptor antibody for psoriasis. N Engl J Med 366: 1181-1189, 2012.

16. Wilson MS, Madala SK, Ramalingam TR, Gochuico BR, Rosas IO, Cheever AW and Wynn TA: Bleomycin and IL-1 $\beta$-mediated pulmonary fibrosis is IL-17A dependent. J Exp Med 207: 535-552, 2010.

17. Gasse P, Riteau N, Vacher R, Michel ML, Fautrel A, di Padova F, Fick L, Charron S, Lagente V, Eberl G, Le Bert M, Quesniaux VF, Huaux F, Leite-de-Moraes M, Ryffel B and Couillin I: IL-1 and IL-23 mediate early IL-17A production in pulmonary inflammation leading to late fibrosis. PLoS One 6: e23185, 2011.

18. Liu H, Li Z, Lv XX and Mi S: Neutralization of IL-17A activity can improve pulmonary function in mice with pulmonary fibrosis. Hang Tian Yi Xue Yu Yi Xue Gong Cheng 26: 38-42, 2013 (In Chinese)

19. Fan XM, Zhang SB, Liu CT, Xiong B and Wang ZL: STAT1 antisense oligonucleotides inhibit secretion of TNF-alpha, IL-8 and $\mathrm{NO}$ in alveolar macrophages of rats suffering from interstitial pulmonary fibrosis. Xi Bao Yu Fen Zi Mian Yi Xue Za Zhi 22: 487-489, 2006 (In Chinese) 